\title{
Geografia e Cartografia escolar: o que sabem e como ensinam professoras das séries iniciais do Ensino Fundamental?
}

Adriano Rodrigo Oliveira

Universidade de Oviedo

\section{Resumo}

Este texto resulta de parte de uma investigação sobre saberes e práticas de professoras das séries iniciais com o uso de atlas municipal escolar. Buscamos com esta investigação nos aproximar de uma análise das práticas docentes de duas professoras de $4^{\text {a }}$ série do Ensino Fundamental da rede estadual no município de Limeira no interior paulista. Neste artigo, procuramos identificar processos que estruturam e caracterizam as atuações dessas professoras com o uso das páginas temáticas e mapas escolares do atlas municipal, enfocando principalmente não mais as formas de construção de conhecimentos com o atlas, mas sim qual a base de conhecimentos, e quais são os saberes que estruturaram as situações de ensino promovidas por elas com o uso desse material didático em sala de aula. Utilizando fundamentos metodológicos de uma abordagem qualitativa da pesquisa educacional, podemos concluir que os saberes das professoras acerca de conhecimentos cartográficos têm sua origem na experiência cotidiana do trabalho docente; envolvem saberes advindos principalmente do contato e da experiência com outras professoras; das imagens e memórias de quando eram alunas; e do uso de livros didáticos. Verificamos com os sujeitos desta investigação que o atlas gera no contexto escolar processos de ensino e aprendizagem motivadores no sentido de tratar de problemáticas locais vivenciadas tanto pelas professoras como pelos alunos.

\section{Palavras-chave}

Atlas escolar - Didática da Geografia e Cartografia - Saberes docentes. 


\section{Geography and school Cartography: what do teachers from the initial series know and how do they teach?}

Adriano Rodrigo Oliveira

Universidade de Oviedo

\begin{abstract}
This text results from an investigation on knowledges and practices of teachers of the initial series of Fundamental Education and their use of the school municipal atlas. We have sought in this study to inspect closely the teaching practices of two teachers of the fourth grade of Fundamental Education in a state school of the city of Limeira, State of São Paulo. The article seeks to identify processes that structure and characterize the actions of these teachers with the use of theme pages and school maps of the municipal atlas, focusing particularly not so much on the forms of construction of knowledge with the atlas, but on the basis of the knowledge and on which knowledges help to structure the teaching situations promoted by the teachers with the use of these didactic materials in the classroom. Making use of methodological foundations of a qualitative approach to educational research, we reached the conclusion that the knowledges of these teachers about cartographical facts have their origins in the daily experience of their teaching work; they involve knowledges that come from the contact with other experienced teachers; from images and memories of the time when they themselves were students; and from the use of textbooks. We observed with the subjects of this investigation that the atlas gives rise in the school context to stimulating teaching and learning processes, in the sense of dealing with local problems experienced both by teachers and by pupils.
\end{abstract}

\section{Keywords}

School atlas - Didactics in Geography and Cartography - Teachers' knowledges. 
0 presente artigo é resultado de uma investigação sobre a geografia e cartografia que se ensina na escola e tem como foco de análise a prática docente de professoras das séries iniciais do Ensino Fundamental. Resulta do desdobramento de nossa participação no projeto intitulado: Integrando universidade e escola por meio da pesquisa em ensino - Atlas Municipais Escolares', desenvolvido em colaboração com professores da rede estadual paulista de ensino e da UNESP de Rio Claro (SP).

Como já citamos em outro trabalho publicado (Oliveira, 2003), o projeto do "Grupo Atlas de Rio Claro" ${ }^{2}$ resultou na publicação de três atlas municipais escolares que foram distribuídos para as escolas de Ensino Fundamental dos municípios de Limeira, Ipeúna e Rio Claro, de maneira que os professores das séries iniciais pudessem recorrer a esse material didático para ensinar aspectos geográficos, históricos e ambientais das localidades citadas.

Apoiados na literatura disponivel sobre didática da Geografia e da Cartografia, encontramos poucos estudos sobre os saberes de professores e o ensino de conteúdos das didáticas específicas, como estas, que se ensinam na escola.

Notamos ser consenso entre os pesquisadores brasileiros e internacionais da área de Cartografia Escolar que ensinar o mapa para os escolares e compreender o seu processo de ensino e aprendizagem são desafios permanentes para os professores da escola fundamental (Alvarez Orellana, 2002; D’Angelo, 2004; Castellar, 2005; Wiegand, 2006; Bomfim, 2006; Cazetta, 2007). Dessa forma, pensamos que realizar pesquisas sobre como professoras realizam seu trabalho de ensinar por meio da linguagem cartográfica na escola é de fundamental importância para compreendermos o processo de ensino de mapas. Diversos investigadores apontam a pesquisa sobre ensino e aprendizagem da linguagem cartográfica na escola como relevante para a melhoria da educação geográfica (Cavalcanti, 1998; Fontanabona, 2000; Straforini, 2004; Callai, 2005; Oliveira, 2005).

Considerando a literatura escassa sobre pesquisas com o ensino de mapas e a prática docente, estamos convencidos da necessidade de investigações que persigam a compreensão do cotidiano escolar, dos saberes e do trabalho docente com o uso de mapas na sala de aula, sendo que o domínio da linguagem cartográfica é fundamental para aprender geografia na escola. Lembramos também que mapas são utilizados no ensino de história e ciências, o que reafirma a importância da cartografia.

Buscamos com esta investigação nos aproximar de uma análise das práticas docentes de duas professoras de $4^{\text {a }}$ série do Ensino Fundamental da rede estadual do município de Limeira no interior paulista. Neste artigo, procuramos identificar processos que estruturam e caracterizam as atuações dessas professoras com o uso das páginas temáticas do atlas municipal escolar, enfocando principalmente não mais as formas de construção de conhecimentos com o atlas (Oliveira, 2003), mas sim qual a base de conhecimentos, e quais são os saberes que estruturaram as situações de ensino promovidas por elas com o uso desse material didático em sala de aula.

Caminhando para a discussão dos dados deste trabalho, delimitamos o recorte de análise à identificação e compreensão, partindo da observação das práticas docentes. As reflexões aqui apresentadas são resultado dos saberes docentes como estruturantes da ação das professoras com o uso do atlas municipal. Com o objetivo de apresentar a construção dessa categoria de análise, passamos a descrever e analisar situações concretas de ensino, tendo como foco central a prática dessas duas professoras.

\section{Saberes docentes como estruturantes da intervenção didática em sala de aula}

A professora Fátima ${ }^{3}$ desenvolve sua aula por meio da página temática "Águas na cidade".

1. Coordenado pela Profa. Dra. Rosângela Doin de Almeida, financiado pela FAPESP (1997-1999) e, posteriormente, em segunda fase, pelo programa de financiamento de pesquisas sobre o Ensino Público (2002-2004).

2. Um maior aprofundamento sobre os alcances e resultados do projeto do Grupo Atlas de Rio Claro pode ser encontrado na revista Cadernos Cedes n. 60 da UNICAMP (2003) em seu exemplar intitulado "Formação de professores e atlas municipais escolares".

3. Esse nome é fictício, assim como o da professora Heloisa. 
A aula tem início depois que o pesquisador traz da biblioteca todos os atlas escolares que ficam guardados com a bibliotecária.

Profa.: “... Agora vamos estudar o atlas, abram na página 78 que fala sobre a situação da água na nossa cidade... vamos ler o texto que tem aí...."

Apesar de, na sua fala, a professora apontar a ação de leitura na primeira pessoa do plural, indicando a leitura de todos, na realidade ela faz sozinha, em voz alta, a leitura do texto da página temática.

Essa página apresenta um conceito de bacia hidrográfica ao enunciar que existe uma do rio Piracicaba e que esta envolve bacias menores como do ribeirão Tatu, da Graminha, Água da Serra, e que também incluem seus afluentes: os córregos da Barroca Funda, da Bovinha etc.

Sabemos que o ensino de conceitos de hidrogeografia por meio da hierarquia hidrográfica exige da professora habilidades de contextualizar essas diferentes escalas para avançar no processo de ensino e aprendizagem de conceitos geográficos. Entretanto, apesar da dificuldade da professora e dos alunos com as diferentes escalas de análise, os conhecimentos que a professora Fátima dispõe do município de Limeira permite que ela avance além do conteúdo apresentado pelo atlas escolar.

Em sua aula, essa professora demonstra grande intimidade com parte do conteúdo prático do atlas escolar, já que este faz parte de seus conhecimentos cotidianos do lugar. São conhecimentos oriundos de relações estabelecidas entre o habitante e o lugar (Carlos, 1986).

Profa.: “... o ribeirão do Tatu passa aqui na frente da nossa escola, ele está canalizado. Quem vem do centro da cidade tem que atravessar o viaduto e dali dá pra ver o ribeirão Tatu..."

Aluno.: “... então este é o ribeirão que passa pela cidade...”
Profa.: “... o ribeirão Tatu corta a cidade quase que no meio e ele em uma parte acompanha a ferrovia. Pode ver que onde tá o ribeirão é mais baixo o terreno, e fica mais plano então, é este o caminho da estrada de ferro. Alguém que vem lá da vila Giotto ou da vila Pizza desce um pouco o terreno para chegar até perto da ferrovia... olhem no mapa do atlas..."

Todos os alunos conhecem o ribeirão Tatu, representado no mapa do atlas. No entanto, ficam surpresos ao saber que todo o ribeirão está poluído, pois pensavam que a poluição se restringia apenas às proximidades da escola, onde funcionavam antigas fábricas de bebidas e papel.

Os alunos perguntam então por quais bairros o ribeirão Tatu passa. A professora vai até a lousa e faz um desenho simplificado do mapa de Limeira e se esforça em localizar os bairros que ela conhece. Em alguns desses bairros moram alunos da classe.

Nessa tentativa de localizar os bairros por onde passa o ribeirão Tatu, a professora percebe que o mapa que acompanha a página temática não apresenta a nomeação dos principais bairros, e os alunos concluem que apenas na área central da cidade ocorre a canalização.

A professora tira do seu armário um mapa e guia do município de Limeira. Nesse mapa, existem as principais vias, praças e áreas verdes do município. Mostra para os alunos a localização da escola, a estrada de ferro e o percurso do ribeirão Tatu.

Profa.: “... deu pra entender por onde passa o ribeirão Tatu? Neste mapa antigo de Limeira, tem todos os bairros do centro da cidade e seus nomes..."

0 fato de a professora conhecer o relevo da cidade de limeira, onde estão as terras altas e baixas e o trajeto do ribeirão Tatu, facilita a condução de sua aula, e permite que os alunos elaborem questões que extrapolam o conteúdo da página temática. 
A professora volta novamente no seu armário e começa a procurar fotografias antigas que havia guardado.

Notamos um arsenal de fotos, jornais, boletins regionais e revistas da cidade de Limeira. Encontrando uma revista com folhas verdes, ela procura algo sobre fotos antigas que mostrem o ribeirão Tatu, porém não consegue achar o material que procura.

Essa situação ilustra a tendência dos professores para reinventar a intervenção em sala de aula, e se aproxima muito do conceito de bricolage de Philippe Perrenoud (1993).

Segundo Perrenoud (1993), quando os professores não estão satisfeitos com os meios de ensino ou quando percebem que estes não levam aos seus resultados esperados, levam uma parte do seu tempo a procurar histórias, textos, imagens, informações e objetos que possam permitir a realização de um projeto ou então os guardam porque acham que um dia poderão ser úteis ao trabalho escolar.

Concordamos com Perrenoud (1993) ao afirmar que a pesquisa educacional deveria investir na compreensão e descoberta do trabalho realizado pelos professores em situações práticas de sala de aula. É preciso investir no enriquecimento do conjunto dos materiais a partir dos quais o professor fabrica.

Em outra situação de ensino, utilizando a linguagem cartográfica, a professora Fátima desenvolve a aula com a página temática " $\mathrm{Li}$ meira Divisão Político-Admistrativa”. Começa a aula com uma pergunta aos alunos:

Profa.: “... Vocês conhecem o município?...”, “... então agora vamos abrir o atlas na página 40 com o tema Limeira e sua divisão político-administrativa...”

Profa.: "... o que quer dizer divisão político-administrativa?...", "... quer dizer que a administração é feita pelo prefeito e seus vereadores...”

Ao mesmo tempo que a professora conduz a aula perguntando aos alunos, também já oferece a resposta. Após pedir aos alunos para lerem o texto do atlas, a professora começa a fazer a leitura em voz alta de cada parágrafo da página temática.

$\mathrm{Na}$ página temática, há um gráfico que informa a porcentagem de população urbana de Limeira, que é de $85 \%$ contra $15 \%$ de população rural.

Após a leitura feita pela professora e os alunos da página do atlas, a professora conclui:

Profa.: “... Limeira é uma cidade muito urbanizada, urbanizada é uma palavra que vem de urbano que significa cidade... e vemos também que no texto mostra que a área total do município é de $597 \mathrm{~km} 2$, sendo $24 \%$ da área urbana e $76 \%$ da área rural, como podemos representar isso?...”

Profa.: “... Vamos fazer um quadriculado, se tivermos uma área de 100 quadradinhos, e destes 24 são da área urbana, é claro que os outros 76 serão da área rural... então qual é maior a zona urbana ou a rural?..."

A professora faz um quadrado na lousa, depois faz outros quadriculados para representar 100 unidades iguais. Escolhe uma área do quadrado maior composta de 24 quadrados menores e pinta de vermelho os que representam a área urbana. Depois forma na lousa uma representação que expressa a quantidade de quadrados associados à porcentagem estabelecida pela informação do atlas.

Notamos, no entanto, que alguns alunos não compreendem como um município muito urbanizado, como dito pela professora, tem sua área rural maior que a urbana.

Avançando na leitura e explicação do texto, a professora fala sobre os municípios que fazem limite com Limeira, depois pede aos alunos para fazerem uma cópia do texto:

Profa.: “... agora façam a cópia do texto do atlas de Limeira no caderno para fazermos uma atividade depois..." 
No atlas, a informação sobre a população do município era do censo de 1996. A professora, então, preocupada em atualizar os dados do atlas e levar essa informação para os alunos, vai até a secretaria da escola para conseguir informação através do IBGE local sobre a população em 2001. Conseguida a informação de que a população atual de Limeira é de 262 mil habitantes, pede aos alunos para atualizarem os dados do atlas.

Depois que os alunos copiam o texto da página do atlas no caderno, a professora distribui um mapa político-administrativo do município de Limeira, o mesmo mapa do atlas, porém reduzido e sem os nomes dos municípios vizinhos. Para prepará-lo, ela tirou os nomes dos municípios com corretivo e depois fez o xerox reduzido.

0 desenvolvimento dessa atividade surge da experiência da professora em ensinar os referenciais de localização geográfica: leste, oeste, norte e sul.

A atividade tem como objetivo ensinar a localização de área urbana e área rural, porém com uma outra legenda, diferente da estabelecida pelo atlas municipal. Para tanto, ela pede aos alunos para fecharem o atlas escolar e guardar embaixo da carteira, só podendo ficar com o caderno que possuía as informações sobre os municípios.

Profa.: “... Vou entregar um mapa do município de Limeira e vocês guardem este atlas embaixo da carteira..."

Profa.: “... pintem com o lápis marrom a área urbana que é a cidade, onde tem a prefeitura etc... A área rural vocês devem pintar de verde, podem contornar o limite do município de Limeira com preto pra destacar das outras cidades..."

Profa.: “... depois de pintar o mapa, vocês vão colocar a legenda também, faz um quadrado no lado e pinta de marrom e escreve área urbana, depois área rural e pinta de verde... depois vocês, olhando no caderno e seguindo as orientações geográficas, vocês vão colocar o nome dos municípios limites com Limeira..."

Os alunos ficam confusos e alguns não entendem a proposta de atividade da professora. Percebemos que muitos erram demostrando que não têm domínio do que está a norte, sul, leste ou oeste de Limeira.

Notamos que questões relativas à localização e orientação são pouco esclarecidas para as professoras das séries iniciais, geralmente elas concebem que o norte está para cima e o sul para baixo, o que leva a uma compreensão errônea na leitura de mapas.

Apesar de o texto no caderno dos alunos apontar os municípios que estavam a norte, sul, leste e oeste de Limeira, os alunos localizaram errado os municípios vizinhos.

No fim da aula, a professora Fátima nos diz que ficou muito preocupada com a dificuldade apresentada pelos alunos, e que essa era a primeira vez que tentava ensinar divisão política de uma forma diferente, por meio do mapa municipal.

Outra interpretação sobre essa mesma situação didática diz respeito à transformação que a professora faz do material didático, construído dentro de uma concepção de ensino relacionada à proposta cartográfica da semiologia gráfica.

Quando a professora solicita para os alunos criarem outra simbologia sobre o mapa de relevo do atlas, ela desconsidera que o mapa já apresenta uma legenda que possui em si a representação de uma variável valor. Segundo Martinelli (2001), essa representação permite uma visualização e percepção ordenada das categorias escolhidas, assim a gradação de cinzas para representar as altitudes no mapa de relevo permite a criação de uma escala que, segundo a proposta da semiologia, vem facilitar a leitura do mapa.

Parece que, para a professora, o importante é determinar uma outra simbologia. Seguindo sua tradição com o uso de livros didá- 
ticos, o ensino do relevo por meio de mapas deve ser realizado com as cores que são comuns em mapas dos livros didáticos.

lsso vem de encontro com as afirmações feitas por Audigier (1997) sobre a influência dos livros didáticos na construção das concepções dos professores sobre a disciplina escolar geografia. Poderíamos identificar, nesse caso, o que se define como uma "vulgata", ou seja, um conjunto de conhecimentos compartidos pelos professores no ensino, e isso reflete o processo de construção de uma versão do conhecimento escolar que tem influências na aprendizagem dos alunos. No caso da situação analisada, definiu-se que sempre as terras baixas serão verdes e terras altas, marrom.

Compreendemos que a cartografia ensinada nas escolas torna-se uma construção particular da cultura escolar e que, muitas vezes, está distante dos avanços da ciência de referência, no caso, a Cartografia.

Rodríguez Lestegás (2000) e Martinelli (2001) nos alertam também para o fato de que tanto a geografia como a cartografia, no âmbito escolar, transmitem e reproduzem conhecimentos e competências que, desse modo, criam representações que podem tornar-se uma fonte de erros.

[...] na tradição cartográfica, as cores estão sacramentadas como símbolos, as cores podem criar confusões no sentido associativo, o verde sugere vastas áreas de densa vegetação ou o amarelo ocre um extenso deserto [...]. (Martinelli, 2001, p. 80)

[...] a geografía escolar é uma construção particular por meio da qual se transmite as novas gerações um conjunto de competências [...], a escola seleciona conhecimentos e determina modalidades de transmissão e controle, assim os alunos e professores envoltos e adscritos nesta socialização disciplinar, constroem ao longo de sua escolaridade, representacões desta disciplina, do que é um mapa, do que é um rio [...]. (Audigier, 1997, p. 30)
0 atlas foi construído por professores que receberam orientação sobre o uso de modelos de representação gráfica, porém a instituição escolar colabora na construção de representações e concepções sobre o que é e o que deve ser ensinado em determinadas disciplinas curriculares.

Audigier (1997) assinala que muitos professores têm suas práticas estabelecidas não em modelos ou em cursos oficiais de formação, mas também e principalmente nos métodos que se referem a tradição e memória, o que o autor chama de experiência como professor e antigo aluno. Dessa forma, poderíamos dizer que a prática de ensino tem embutida em si um conteúdo histórico, ou seja, as bases do conhecimento e da ação dos professores estão fortemente assentadas nas concepções construídas também como alunos.

Num primeiro momento dessa aula, a professora associou área do município com população, o que criou certa confusão na análise e interpretação dos dados expostos. 0 atlas usa diferentes linguagens para expressar esses dados. 0 texto mostra que a maior parte do município tem área rural, porém o gráfico mostra que a maior parte da população vive em área urbana. Verificamos que integrar essas informações não era o objetivo central da professora, mais sim utilizar seu conhecimento sobre o uso de porcentagens e explicar de maneira "prática" o que significava e representava os dados de porcentagem de área urbana e rural.

Parece ter ficado muito confuso para os alunos e também para a professora a proposta do atlas de apresentar essas informações. Outra consideração importante é o fato de a professora ter demonstrado um enorme esforço para explicar e ensinar um conhecimento novo, pouco explorado em seu cotidiano. Dessa forma, ela recorre a seus esquemas anteriores, baseados no ensino de porcentagem por meio de papel quadriculado.

Não tendo papel, ela vai para lousa, desenha e simula um quadrado, divide em espaços iguais e tenta ensinar o espaço urbano e rural li- 
near do mapa como se fosse algo quadriculado e formal. Com isso, perde-se a dimensão de linearidade e espacialidade que o mapa apresenta.

Parte desse episódio nos lembra o exposto por Tardif (2002) sobre o trabalho das professoras:

[...] o que a pesquisa sobre os saberes profissionais mostra é que eles são fortemente personalizados, ou seja, que se trata raramente de saberes formalizados, de saberes objetivados, mais sim de saberes apropriados, incorporados, saberes que são difíceis dissociar das suas experiências e da situação de trabalho [...]. (p. 25)

Outro aspecto que destacamos é a atividade elaborada pela professora: primeiro a cópia do texto, posteriormente, ela refaz o mapa do atlas com o objetivo de ensinar os referenciais de localização geográfica, a localização dos municípios vizinhos e a área urbana e rural.

Essa atividade nos remete aos "exercícios tipo" que estão estreitamente relacionados às disciplinas escolares. Como assinala Rodríguez Lestegás (2000) e Audigier (1997), os mapas, quando não são utilizados para pensar geograficamente o espaço, são utilizados para a aquisição da "vulgata" ou seja, para nomear e localizar lugares.

Observamos que a professora pede para os alunos refazerem o mapa do atlas, e ela estabelece a legenda com as cores verde para área rural e marrom para urbana. Como aponta Martinelli (2001), a cor verde torna-se um símbolo quando representa sempre espaços de cultivo e agricultura, e isso vem sendo sempre transmitido na escola. Seria relevante desenvolver atividades com os alunos e professores que busquem encaminhamentos para refletir sobre as escolhas das simbologias na legenda dos mapas.

Audigier (1997) aponta que as disciplinas escolares além de exercícios tipo apresentam também um vocabulário específico. Sendo assim, poderíamos dizer que o ensino de mapas e a cartografia escolar têm uma nomenclatura específica. Nesse caso, a cor verde seria como o símbolo ou nome de tudo que lembra o rural ou a agricultura.

A professora Heloisa também demonstra indícios de dificuldade no entendimento da escala e legenda de mapas. Acompanhamos o desenvolvimento de uma atividade na qual a professora solicita aos alunos para pintarem no mapa político do Brasil, no caso, uma fotocópia de um mapa político, os locais onde os indígenas viviam. Esses dados foram retirados de um mapa encontrado em um encarte do folheto do IBGE que data de 2000.

$A$ aula estava relacionada ao tema "Os primeiros habitantes” e, como era semana comemorativa do Dia do Indígena, a professora aproveitou para inserir atividades com mapas para ensinar a localização dos parques indígenas no Brasil.

Distribuiu para os alunos um mapa fotocopiado do livro didático, retirou título, escala e todas as referências. Ela pediu para os alunos recortarem o mapa bem próximo das bordas dos limites, no caso, o Oceano Atlântico e os demais países com os quais o Brasil faz fronteira. 0 mapa fica solto, apenas com os nomes dos estados.

Com o mapa do encarte do IBGE exposto na lousa, a professora estabeleceu outra legenda, diferente da do mapa original. Ela reagrupou em três categorias que são: 1) cor amarela para os Parques Indígenas com mais de 10.000 habitantes; 2) cor vermelha para os Parques com até 10.000 de habitantes; e 3) cor verde para lugares onde não existem indígenas. $\mathrm{Na}$ lousa, ela desenha uma oca para cada categoria, ou seja, uma oca de cor amarela, outra oca de cor vermelha e uma oca verde para os lugares onde não existem indígenas.

Pede para os alunos pintarem, no mapa político do Brasil fotocopiado, os locais onde vivem os indígenas atualmente conforme a legenda estabelecida.

Notamos que os alunos ficaram confusos e a atividade acabou criando uma visão errônea e uma distorção completa do fenômeno representado no mapa do IBGE. 0 mapa do cader- 
no de uma aluna demonstra uma leitura bastante questionável da distribuição dos indígenas no Brasil.

Verificamos a intenção da professora de simplificar e criar uma nova proposta de representar a população indígena brasileira, porém a atividade elaborada pela professora veio demonstrar sua dificuldade em compreender que o mapa do IBGE apresenta uma escala diferente da do mapa fotocopiado e entregue aos alunos. Querer transpor informações de mapas em escalas diferentes gera possíveis distorções nos fenômenos representados.

Quanto a legenda desenvolvida pela professora Heloisa, verificamos uma confusão na representação da informação. Ela associou oca verde com inexistência de indígenas: se não existem, é contraditório utilizar o símbolo de uma oca. Também verificamos que nos mapas dos alunos existem muitos espaços em branco. Nesse caso, os espaços em branco no mapa também podem ser interpretados como lugares onde não existem indígenas.

Apesar de nessa aula a professora não utilizar um mapa municipal do atlas de Limeira, observamos também dificuldades da professora em avançar numa melhor exploração dos conteúdos dos mapas temáticos. Na maior parte das vezes, as práticas de ensino com mapas ficam apenas no caráter de localização e sem avançar em discussões qualitativas dos fenômenos representados, de modo que possam ser questionados "o que?", "em que ordem?" e “quanto?”, como propõe Martinelli (2001).

Em outra situação didática, a professora Heloisa dá início à sua aula com a página de relevo de Limeira. Pede aos alunos para lerem o texto do atlas, depois passa a explicar com palavras mais simples o que é altitude e vale, conceitos geográficos presentes no texto da página. Segue mostrando as fotos e o perfil topográfico, explica o corte que foi delimitado, depois pede aos alunos para irem ao mapa de relevo.

Profa.: “... Olhem o mapa de relevo, do seu lado tem uma legenda que explica a altura, cada cor diz quantos metros tem o terreno...", “... o ponto mais alto é o Morro Azul, lembram do texto? Quantos metros ele tem mesmo ?..."

Aluno.: “... são 831 metros, é o ponto mais alto de Limeira..."

Profa.: “... e a escola onde fica neste mapa? Em que altura nós estamos?..."

Os alunos fazem silêncio.

Profa.: “... olhe aqui no mapa, a escola está perto do ribeirão Tatu, então qual é a nossa altura?...”

Aluna: “... é o cinza claro, estamos em 500 metros...”

Percebemos que a professora procura estabelecer um diálogo com os alunos e estimula a leitura do mapa, porém na tentativa de facilitar a compreensão dos alunos sobre o conceito de altitude, constrói um erro. Altitude não é o mesmo que altura. Altitude tem relação estrita de distância com o nível do mar, e altura é a distância do chão.

A aula segue e a professora continua na página $77 \mathrm{com}$ a temática "Os mananciais e as áreas de proteção ambiental”, comentando que o relevo é atravessado pela bacia do ribeirão Tatu.

Após a leitura do texto, a professora faz a tentativa de comparar o mapa de relevo de Limeira com o mapa de bacias do rio Piracicaba e Capivari.

Profa.: “... Vamos procurar neste mapa o ribeirão Tatu para ver como está a qualidade de água ....”

Por alguns minutos, a professora e os alunos procuram localizar o ribeirão Tatu. Após alguns minutos, a professora percebe que o mapa de Bacias do Rio Piracicaba tem uma escala diferente da do mapa de relevo. 
Essa confusão inicial revela a dificuldade das professoras em trabalhar com mapas municipais em escalas diferentes. Na tentativa de comparar e sobrepor diferentes temáticas dos mapas do atlas, acabam algumas vezes por confundir mapas de escalas geográficas diferentes.

Em uma aula da professora Fátima, por exemplo, observamos outra situação em que a problemática da escala reaparece. Para desenvolver o conceito de escala geográfica com os alunos, a professora trabalha com papel quadriculado e uma fotocópia de uma atividade que retira do livro Geografia em mapas - o estado de São Paulo, de autoria de Graça Lemos e Marcelo Martinelli.

Nesse livro didático, há uma atividade de escala e representação na qual, por meio de diversos pontos espalhados num retângulo quadriculado, o aluno é conduzido a representar a forma do mapa do estado de São Paulo.

0 trabalho da professora leva a entender que a sua concepção de escala está muito próxima do que chamamos de escala de área.

Profa.: “... Imaginem um quadrado de 10 $\mathrm{cm}$ (desenhou), agora eu vou dividir em $1 \mathrm{~cm}$, dividimos na vertical e horizontal..."

Desenha na lousa 1 metro quadrado. Depois escreve na lousa: $1 \mathrm{~m}$ tem $10 \mathrm{dm}, 1 \mathrm{~m}$ tem $100 \mathrm{~cm}, 1=10 \mathrm{dm}, 1=100 \mathrm{~cm}$ e $1=1000 \mathrm{~mm}$.

0 que compreendemos de sua explicação é o que sabemos sobre escala de área. Esta é utilizada na projeção do planisfério de Peters, que busca uma representação dos países de forma mais igualitária.

No entanto, a escala em mapas do atlas utilizado é linear, envolvendo o conceito de proporção e redução, e não pode ficar vinculada a sistemas métricos de medidas.

A prática da professora revela que parte de seus conhecimentos sobre o uso da escala para o ensino de mapas está baseada nos livros didáticos de geografia. 0 que concluímos é a possibilidade de a professora ter sido induzida pela lógica do exercício do livro didático que enqua- dra a escala e a representação dentro de um sistema quadriculado, que pode levar a compreender a escala num sistema métrico de medidas.

Apenas considerar a escala cartográfica, tal qual se emprestou da geometria, pode levar a uma visão enviesada de fenômenos geográficos atuais, ou seja, não considerar as interrelações existentes entre o local, regional e global afeta a compreensão da diversidade de maneiras que se organiza o espaço geográfico.

Atualmente para se compreender o espaço geográfico, é necessário uma integração entre diferentes escalas de análise, bem como suas relações entre os diferentes níveis. Entretanto, o que vemos na prática da professora é uma forte tradição em se ensinar escala como aparece nos livros didáticos: como algo fechado dentro de um conceito geométrico, ou seja, a escala se expressa como uma fração. Não que isso deixe de ser relevante. Acreditamos que é necessário dominar a construção de uma escala cartográfica, gráfica e saber ler e manejar um mapa com esses elementos, porém a geografia escolar pode avançar para uma compreensão do discurso geográfico, aproximando-se do entendimento das escalas de análises e de suas relações.

Raffestin (1983) alerta para o esclarecimento que devemos ter no ensino de geografia sobre o uso da escala geográfica. 0 autor chama atenção para a importância da escolha da escala de análise de um fenômeno, pois alguns fenômenos podem ser representados em uma determinada escala, e outros podem não ser representáveis ou ter seu significado alterado.

0 trabalho em sala de aula com diferentes escalas de análise perpassa por um domínio e conhecimento da professora: a mudança da escala corresponde a uma mudança do nível de análise e, portanto, corresponde a uma mudança no nível de conceituação (Batllori, 2002), ou seja, quando se modifica a escala, pode se ter recortes na informação. Como exemplifica Roser Batllori (2002):

\section{[...] no caso da geografia urbana o conceito de bairro corresponde a escala local, aglo- meração urbana a escala regional e redes}


urbanas a escalas nacionais e internacionais, a compreensão destes conceitos implica em muitos casos na mudança de mapas, também das características estruturais e de informação [...]. (p. 17)

Quando a professora Heloisa solicita aos alunos para compararem e localizarem o mapa de relevo de Limeira (escala local) com um mapa da bacia hidrográfica do Piracicaba (escala regional), cria uma impossibilidade de análise. Podemos verificar que a escala maior do mapa da Bacia não permite localizar o Ribeirão Tatu.

A questão do entendimento das possibilidades da escala de análise torna-se relevante no ensino de cartografia e geografia já que permite construir conceitos mais complexos para a compreensão do espaço geográfico representado. Como a própria professora aponta, esses temas são pouco discutidos nos cursos de formação inicial e continuada de professores para as séries iniciais. Talvez um melhor esclarecimento sobre esse tema venha a colaborar para um avanço e entendimento na análise de mapas e atlas escolares.

0 que também nos chamou atenção sobre a prática docente e sua realidade multifacetada é o que expõe Tardif e Raymond (2000):

\section{[...] todos os saberes são usados pelos pro-} fessores no contexto de sua profissão e de sala de aula. Os professores utilizam seus conhecimentos pessoais e um saber-fazer personalizado, trabalham com o programa dos livros didáticos, baseiam-se em saberes escolares relativos às matérias ensinadas, guiam-se pela sua própria experiência e ainda retêm certos elementos de sua formação profissional [...]. (p. 215)

Nesse sentido, o saber docente está na confluência entre várias fontes de saberes provenientes da história individual, da sociedade, da instituição escolar, dos outros lugares educativos e dos lugares de formação.

Precisamos avançar nessa caminhada em busca de compreender as lógicas de ensino, os saberes das professoras, suas angústias e condições de trabalho, partindo disso para uma possível transformação e melhoria da qualidade do ensino das didáticas específicas, em nosso caso, a geografia e a cartografia escolar.

\section{Algumas considerações finais}

Este trabalho buscou identificar e compreender a prática docente de duas professoras das séries iniciais do Ensino Fundamental com o uso de mapas municipais do atlas municipal escolar de Limeira, municipio do interior paulista. Perseguimos também a identificação das dificuldades e dos modos de produção do trabalho docente com o uso do atlas municipal escolar.

Essas professoras empreenderam e mobilizaram saberes com o uso de um novo material didático, o que gerou uma nova situação didática de ensino em sala de aula (Lastória; Gonçalves; Oliveira, 2006).

Verificamos que o atlas municipal escolar constitui-se em um material didático elaborado dentro da concepção de ensino que pode levar a uma melhor compreensão crítica e reflexiva acerca da realidade local (Almeida, 2001). No entanto, percebemos que são as concepções e os modelos didáticos construídos pelas professoras ao longo da vida escolar e profissional é que orientam e determinam as formas de construção do conhecimento construídas na sala de aula.

Utilizar os mapas do atlas apenas como transmissão de conhecimentos elimina a possibilidade de participação e elaboração por parte dos alunos de um novo conhecimento sobre o lugar, sobre a sua localidade, o que pode vir a impedir uma análise e compreensão da geografia local.

Como verificamos por meio das práticas apresentadas, o ensino por meio do atlas reproduz, em contexto escolar, aspectos relativos ao modelo disciplinar da geografia, ou seja, atividades como copiar textos e mapas, pintar e colorir mapas, elencar nomes dos rios etc. ainda são bastante comuns. De certa maneira, é o que caracteriza a geografia como disciplina escolar. 
Essas práticas que permeiam o processo de ensino não devem ser desconsideradas. Acreditamos que estas, espelho dos saberes docentes, podem ser aproveitadas no processo de formação continuada de professores. Como propõem Mizukami et al. (2002), é preciso criar na formação continuada uma rede de interações que permita às professoras investirem no acesso a novos conhecimentos e na revisão de suas posições.

Outro aspecto que destacamos neste trabalho tem relação com os saberes que as professoras mobilizam para ensinar conteúdos específicos do atlas. Identificamos, por meio das entrevistas e observações de aulas, as dificuldades enfrentadas com o ensino por meio de mapas municipais.

Observamos que os saberes das professoras acerca de conhecimentos cartográficos têm sua origem na experiência cotidiana do trabalho docente, e envolvem saberes advindos principalmente do contato e da experiência com outras professoras, das imagens de quando eram alunas e do uso de livros didáticos.

Compreendemos que o repertório de saberes das professoras analisadas tem forte ligação com o trabalho docente, ou seja, é gestado principalmente no ambiente de trabalho que, neste caso, é o da escola e, portanto, incorpora aspectos da cultura institucional. Constatamos também que o saber da experiência, compreendido como um conjunto de conhecimentos elaborados no continuo da prática, torna-se o reduto do profissionalismo docente.

Referente ao domínio dos conhecimentos específicos do conteúdo dos mapas do atlas, observamos que as professoras demostraram interesse em receber orientações metodológicas para o ensino de conteúdos do atlas municipal, assim como emitiram diversos conceitos dos conteúdos ao longo do processo de ensino. Interpretamos essas constatações como o indicador de possibilidade, interesse e necessidade de ponto de partida para ampliar oportunidades de formação continuada.

Notamos também que a escala e legenda são elementos cartográficos fundamentais para o ensino de geografia no contexto escolar (Piñeiro Peleteiro; Melón Arias, 1997), porém as professoras apresentam dificuldades em associar mapas municipais de diferentes escalas.

Verificamos a necessidade de esclarecer para os professores das séries iniciais conceitos centrais para a construção e elaboração de mapas. Alertamos que os cursos de formação de professores e os programas de formação continuada devem estar atentos para discutir o processo de construção da legenda de um mapa, bem como escala cartográfica e geográfica, dentre outros aspectos da linguagem cartográfica.

Introduzir o professorado das séries iniciais no contexto de uma formação sólida da linguagem da cartografia pode vir a facilitar o estudo da geografia na escola. Nesse sentido, vemos duas possibilidades: a primeira se concretizaria por meio do estabelecimento de um currículo que contemple espaço de discussão desses temas nos cursos de magistério superior e pedagogia; e por segundo e não menos importante, por meio de um processo dialógico e reflexivo de formação permanente, no qual as professoras pudessem refletir sobre suas práticas e avançar rumo a novas aprendizagens.

Como retrata esta pesquisa, o trabalho com mapas municipais no ensino das séries iniciais é algo novo e recente na incorporação das práticas das professoras, pois elas estão acostumadas aos livros didáticos e atlas escolares que apresentam em sua grande maioria planisférios e mapas temáticos regionais.

Sob a ótica de análise desta pesquisa, podemos dizer que o atlas municipal escolar de Limeira representa a possibilidade de construção de novos conhecimentos e inovações para o ensino da localidade, permitindo tanto para os alunos como aos professores tornarem-se conhecedores e investidores mais conscientes da organização do espaço de vivência.

Sugerimos, portanto, a busca de melhores explicações e esclarecimentos do pouco que se sabe sobre a construção desses novos conhecimentos e dessas inovações que podem emergir do uso de atlas municipais escolares, bem como de- 
vemos investir em pesquisas que avancem na busca de identificar e analisar crenças, concepções, valores, hábitos e rotinas dos professores que ensinam geografia e cartografia. Talvez conhecen- do melhor as justificativas dos professores sobre as ações que promovem em sala de aula, possamos criar um diálogo e colaborar na construção de propostas para o ensino da geografia e cartografia.

\section{Referencias bibliográficas}

ALMEIDA, R. D. Integrando universidade e escola por meio de uma pesquisa colaborativa. 2001. Tese (Livre-docência em Prática de Ensino de Geografia). Instituto de Biociências, Departamento de Educaçao da UNESP, Rio Claro, 2001.

ALVAREZ ORELLANA, M. F. El mapa y la formación del profesorado. Didáctica Geográfica, Madrid, n. 5, segunda época, p. 11-41, 2002.

AUDIGIER, F. La géographie scolaire: un modèle disciplinaire puissant. In: KNAFOU, R. (Org.). L'état de la géographie. Autoscopie d'une science. Paris: Belin, 1997. p. 75-79

BOMFIM, N. R. A imagem da geografia e o ensino da geografia pelos professores das séries iniciais. Estudos Geográficos, Rio Claro, v. 4, p. 107-116, 2006.

BATLLORI, R. La escala de análisis: un tema central en didáctica de la geografía. ĺber. Barcelona, n. 32, p. 6-19, 2002.

CALLAI, H. C. Aprendendo a ler o mundo: a geografia nos anos iniciais do ensino fundamental. Cadernos Cedes, Campinas, v. 25, n. 66, p. 227-247, 2005.

CASTELLAR, S. M. V. (Org.). Educação geográfica, teorias e práticas docentes. São Paulo: Contexto, 2005.

CAVALCANTI, L. S. Geografia, escola e construção de conhecimentos. Campinas: Papirus, 1998.

CAZETTA, V. Práticas educativas com fotografias aéreas verticais em uma pesquisa colaborativa. Biblio3W, Barcelona, v. 11, p. 115, 2007.

D’ANGELO, M. L. (Org.). Problemas y propuestas en la enseñanza de la geografía: el uso de materiales cartográficos. Santa Fe: Universidad Nacional del Litoral, 2004.

FONTANABONA, J. (Org.). Cartes et modèles graphiques: analyses de pratiques en classe de géographie. Paris: INRP, 2000.

LASTÓRIA, A. C.; GONÇALVES, A. R.; OLIVEIRA, A. R. Saberes y practicas docentes con el uso de atlas municipales escolares. In: GÓMEZ RODRIGUEZ, A. E.; NUÑEZ GALIANO, P. (Orgs.). Formar para investigar, investigar para formar en didáctica de las ciências sociales. Málaga: Digarza; AUPDCS, 2006. p. 245-253.

MARTINELLI, M. As representações gráficas da Geografia: os mapas temáticos. 2001. Tese (Livre-docência em cartografia temática). Faculdade de Filosofia Letras e Ciências Humanas, Departamento de Geografia da Universidade de São Paulo, São Paulo. 2001.

MIZUKAMI, M. G. N. et al. Escola e aprendizagem da docência: processos de investigação e formação. São Carlos: EdUFSCar, 2002.

OLIVEIRA, A. R. Modelos de enseñanza y aprendizaje con el uso de mapas en los libros de texto de Espana y Brasil. Didáctica Geográfica, Madrid, n. 7, p. 473-485, 2005.

. 0 uso de atlas municipais escolares e as formas de construção do conhecimento em sala de aula: analisando situações de ensino. Cadernos Cedes, Campinas, v. 23, n. 60, p. 218-230, ago. 2003.

PIÑEIRO PELETEIRO, M. R.; MELÓN ARIAS, M. C. M. El papel del atlas en la enseñanza. Íber. Barcelona, n. 13, p. 37-45, 1997. 
PERRENOUD, P. Práticas pedagógicas, profissão docente e formação, perspectivas sociológicas. Lisboa: Publicações Dom Quixote; Instituto de Inovação Educacional, 1993.

RAFFESTIN, C. Escala e ação, contribuições para uma interpretação do mecanismo de escala na prática da geografia. Revista Brasileira de Geografia. Rio de Janeiro, n. 45, p. 122-135, 1983.

- La elaboración del conocimiento geográfico escolar: de la ciencia geográfica a la geografía que se enseña o vice-versa? Íber, Barcelona, n. 24, p. 107-117, 2000.

STRAFORINI, R. Ensinar geografia: o desafio da totalidade-mundo nas séries iniciais. Sao Paulo: Annablume, 2004.

TARDIF, M. Saberes docentes e formação profissional. Petrópolis: Vozes, 2002.

TARDIF, M.; RAYMOND, D. Saberes, tempo e aprendizagem do trabalho no magistério. Revista Educação e Sociedade. Campinas, V. 21, n. $73,2000$.

WIEGAND, P. Learning and teaching with maps. Abingdon; New York: Routledge, 2006.

Recebido em 23.10.06

Aprovado em 19.06.08

Adriano Rodrigo Oliveira, licenciado em Geografia pela UNESP - Rio Claro (SP); mestre em Educação, área de Metodologia do Ensino pela UFSCar; doutorando em Educação, área de Didática da Geografia na Faculdade de Educação da Universidade de Oviedo (Espanha); é pesquisador e bolsista da CAPES na Espanha. 